\title{
ADSORÇÃO DE CÁTION METÁLICO EM POLPA CELULÓSICA MODIFICADA
}

\author{
D. L. BESSA ${ }^{1}$, D. J. SILVA ${ }^{1}$, G. T. DUTRA ${ }^{1}$, R. C. S. SOUSA ${ }^{1}$ e C. R. BELLATO ${ }^{1}$ \\ ${ }^{1}$ Universidade Federal de Viçosa, Departamento de Química e Engenharia Química \\ E-mail para contato: rita.sousa@ufv.br
}

\begin{abstract}
RESUMO - A dureza da água é um fator relevante para o seu consumo industrial e doméstico. Este trabalho foi desenvolvido tendo em vista a busca de métodos alternativos, baratos e verdes, em substituição às resinas de troca iônica, obtidas por derivados de petróleo e comumente utilizadas na adsorção de metais presentes em soluções aquosas. Foi utilizada polpa celulósica modificada como adsorvente para retirar o íons cálcio de amostras de água dura. A polpa Kraft branqueada foi modificada com a incorporação de nanocristais de celulose (CNC) e utilizada na determinação de isotermas de adsorção de cálcio por ensaios em batelada usando a titulometria como método analítico tradicional de quantificação. O sólido adsorvente estudado foi eficiente para adsorver íons cálcio, chegando a remover cerca de 47,66\% concentração inicial, na faixa de concentrações estudada.
\end{abstract}

\section{INTRODUÇÃO}

Os cátions metálicos dissolvidos em água podem trazer diversos prejuízos econômicos (Who, 2004). Nas indústrias, interações entre $\mathrm{pH}$, alcalinidade e temperatura podem causar deposição de sais insolúveis e a formação de crostas no interior de tubulações, equipamentos industriais e sistemas de tratamento e distribuição de água.

Métodos alternativos para remoção de metais vêm sendo estudados nos últimos anos (Karnitz Jr., 2007; De Melo, 2007). Particularmente, a adsorção apresenta as vantagens de baixa geração de resíduos, fácil recuperação dos metais, possibilidade de regeneração do adsorvente e alta seletividade (Kobya et al., 2005). Este tratamento pode vir a se tornar um método para a remoção de íons muito versátil e de vasta utilização pelo desenvolvimento de materiais adsorventes que possuam habilidades de remoção competitivas aos das resinas comerciais. A desvantagem da maioria das resinas comerciais de troca iônica está no fato delas serem obtidas de derivados do petróleo, fonte não renovável e não biodegradável (Mendham et al., 2002), além de possuírem alto custo de aquisição (Orlando et al., 2002).

O desenvolvimento de materiais biodegradáveis de fontes renováveis vem sendo fonte de inúmeras pesquisas nos últimos anos. Nanocristais de celulose (CNC) são estruturas cristalinas altamente ordenadas em materiais celulósicos. Pesquisas com CNC (cujas fontes são abundantes e renováveis) têm atraído grande atenção da comunidade científica, devido à grande área superficial ativa (Dong et al., 2012) e ainda devido à sua funcionalidade para várias aplicações. Assim, este trabalho tem o propósito de investigar a possibilidade de se utilizar nanocristais de celulose do algodão incorporados a polpa Kraft branqueada como matriz de troca catiônica para abrandamento da dureza da água. 


\subsection{Dureza da água}

A água, por ser um ótimo solvente, quando precipita em forma de chuva dissolve os gases existentes na atmosfera (gás carbônico e oxigênio). Ao atingir a terra, parte dela se escoa sobre a superfície, e a outra parcela se infiltra, e ou é evaporada. A água que escoa sobre a superfície, e aquela que se infiltra vão dissolvendo, em sua trajetória, os minerais existentes, como, por exemplo, os carbonatos de cálcio e magnésio (Manahan, 2000). Água com altos teores de cálcio e magnésio é denominada de água dura, embora esses cátions não sejam os únicos que podem produzir dureza na água eles são os principais. A dureza da água é expressa como a massa em miligramas por litro de carbonato de cálcio que contém o mesmo número total de íons bivalentes (Baird, 2002).

Na maioria dos casos, a presença destes sais não tem significado sanitário, ou seja, não influem na sua potabilidade. Porém, os cátions metálicos dissolvidos em água podem trazer prejuízos econômicos desde aos lares até as indústrias. Nos lares, a dureza na água provoca um aumento excessivo do uso de sabão, pois o sabão forma sais insolúveis com os cátions responsáveis com a dureza da água sendo necessário usar uma quantidade maior para a limpeza. Nas indústrias, interações entre o $\mathrm{pH}$, a alcalinidade, temperatura e outras substâncias podem causar deposição de sais insolúveis e formação de crostas dentro de tubulações, sistemas de tratamento e distribuição, caldeiras e outros equipamentos (Who, 2004).

A remoção de cátions metálicos é uma tarefa muito difícil devido ao alto custo do tratamento, especialmente em países em desenvolvimento (Karnitz Jr., 2007). Métodos alternativos para remoção de metais vêm sendo estudados, a exemplo da osmose reversa, da eletrodiálise, da ultrafiltração e da adsorção com bioadsorventes (Meena et al., 2005; Spinelli et al., 2005; Bo Zhu, 2008). Particularmente, a adsorção apresenta vantagens pela baixa geração de resíduos, fácil recuperação dos metais e a possibilidade de regeneração do adsorvente (Kadirvelu et al., 2001; Kobya et al., 2005; Chakravarty, 2008).

\subsection{Processo de adsorção}

A adsorção pode ser definida como o acúmulo de um determinado elemento ou sustância na interface entre a superfície sólida e a solução adjacente (Moreira, 2004). A adsorção apresenta vantagens pela baixa geração de resíduos, fácil recuperação dos metais e a possibilidade de regeneração do adsorvente (Kardirvelu et al., 2001; Kobya et al., 2005) e tem se destacado como um processo de separação, principalmente, pela sua alta seletividade em nível molecular, permitindo a separação de diferentes componentes.

O tratamento por resina é baseado na fixação em uma superfície sólida de grupos funcionais que podem remover os íons da solução. Este tratamento pode vir a se tornar um método para a remoção de íons muito versátil e de vasta utilização pelo desenvolvimento de outros materiais adsorventes de menor custo e que possuam habilidades de remoção competitivas aos das resinas comerciais (Nunes, 2004; Cheremisinoff, 2002; Karnitz Jr., 2007). A desvantagem da maioria das resinas comerciais de troca iônica está no fato delas serem obtidas de derivados do petróleo, fonte não renovável e não biodegradável (Mendham 
et al., 2002) e por isso possuírem alto custo de aquisição (Orlando et al., 2002).

O desenvolvimento de materiais biodegradáveis de fontes renováveis vem sendo fonte de inúmeras pesquisas nos últimos anos. A disponibilidade de biopolímeros, sua abundância na natureza, o baixo custo e a acessibilidade têm despertado o interesse no estudo da aplicação desses (Spagnol et al., 2012).

\subsection{Nanocristais de celulose}

A celulose é o biopolímero natural mais abundante, renovável e biodegradável (Zhou et al., 2011). A unidade repetitiva da celulose é composta por duas moléculas de glicose, que contem seis grupos hidroxilas livres, responsáveis pelas interações inter e intramoleculares. Devido a essas ligações de hidrogênio, há uma forte tendência na celulose de se formar cristais insolúveis em água e na maioria dos solventes orgânicos (Spagnol et al., 2012). Essa região cristalina é envolta por uma região amorfa, resultante da má formação da estrutura, devido à alteração no processo de cristalização.

As regiões amorfas surgem como imperfeições na estrutura cristalina da celulose, tem seus sítios ativos mais acessíveis ao ataque na hidrólise ácida. Devido a este fato e sob condições controladas, a região amorfa pode ser quebrada, liberando as partículas coloidais conhecidas como nanocristais de celulose. Nanocristais de celulose (CNC) são estruturas cristalinas altamente ordenadas em materiais celulósicos. Nos últimos anos, pesquisas com CNC (cujas fontes são abundantes e renováveis) têm atraído grande atenção da comunidade científica, devido à grande área superficial ativa e ainda devido à sua funcionalidade para várias aplicações (Das et al., 2011; Dong et al., 2012).

\section{MATERIAIS E MÉTODOS}

A matéria-prima utilizada neste trabalho, polpa Kraft branqueada de Pinus elliottii foi fornecida pela indústria Suzano Papel e Celulose.

\subsection{Caracterização}

Análise Granulométrica: Este ensaio foi realizado segundo a norma NBR 7181 (ABNT, 1984) a qual estabelece que certa quantidade de amostra seja peneirada por conjunto de peneiras série Tyler (6 a 12) acopladas a uma mesa vibratória.

Microscopia Eletrônica de Transmissão (MET): A solução contendo os nanocristais de celulose foi submetida a análise em microscópio eletrônico de transmissão da marca Zeiss ${ }^{\circledR}$ modelo EM 109 no Núcleo de Microscopia e Microanálise (NMM) da UFV. Seguindo o protocolo do próprio núcleo foram usadas diluições de 10(dez) e 100(cem) vezes da solução em grids de cobre com 300 Mesh e como contraste solução de Acetato de Uranila $2 \%$. 


\subsection{Obtenção dos CNC e incorporação à polpa Kraft branqueada}

A metodologia utilizada na obtenção dos nanocristais de celulose foi adaptada de Sonesso (2011) utilizando-se fibras de algodão. Após obtenção dos CNC, foram adicionados $6,25 \% \mathrm{~m} / \mathrm{m}$ à polpa Kraft branqueada.

\subsection{Isotermas de adsorção}

Para obtenção das isotermas de adsorção, foram adicionados a erlenmeyers $0,0440 \mathrm{~g}$ do adsorvente (polpa Kraft branqueada pura ou polpa Kraft branqueada incorporada com CNC), com $50 \mathrm{~mL}$ da solução sintética de $\mathrm{Ca}^{+2}$ (preparada utilizando-se cloreto de cálcio, $\mathrm{CaCl}_{2}$ ) em concentrações iniciais variando de 50 a $400 \mathrm{mg} . \mathrm{L}^{-1}$, em pHs iguais a 5,7 ou 10 . Os erlenmeyers foram mantidos sob agitação, em temperatura ambiente, durante 3 horas. A concentração dos íons na fase fluida foi avaliada pelo método clássico de titulação volumétrica de complexação em EDTA (Boehm, 2002). Para a titulação foi utilizada uma alíquota de $10 \mathrm{~mL}$ da solução contendo $\mathrm{Ca}^{2+}$. Para uma titulação quantitativa, o pH foi ajustado entre 9 e 11 e 20 gotas de solução de magnésio-EDTA foram adicionadas ao sistema para facilitar a observação do ponto de viragem. O indicador utilizado foi o negro de eriocromo (Erio-T).

A capacidade do adsorvente $\mathrm{q}$ ( $\mathrm{mg}$ do metal/g do adsorvente) foi determinada com base em um balanço de massa no sistema (Equação 1).

$$
q=\frac{V\left(C_{0}-C\right)}{m}
$$

onde q é a quantidade de metal adsorvida $\left(\mathrm{mg} \mathrm{g}^{-1}\right)$, V é o volume da solução $(\mathrm{L}), \mathrm{C}_{0}$ é a concentração inicial do metal $\left(\mathrm{mg} . \mathrm{L}^{-1}\right), \mathrm{C}$ é a concentração do metal após o equilíbrio $\left(\mathrm{mg} . \mathrm{L}^{-1}\right)$ e m é a massa de material adsorvente utilizada $(\mathrm{g})$.

Análise de absorção atômica: A análise foi realizada em espectrômetro de absorção atômica (Agilent, 240 FS AA), lâmpada de cálcio, comprimento de onda de 422,7 nm, óxido nitroso acetileno e fenda de entrada 0,5 .

\section{RESULTADOS E DISCUSSÃO}

\subsection{Caracterização}

A análise granulométrica da polpa Kraft branqueada indicou um tamanho médio de partícula de 3,32 $\mathrm{mm}$.

Na Figura 1 são apresentadas as imagens das micrografias obtidas por MET da amostra de nanocristais de celulose. 


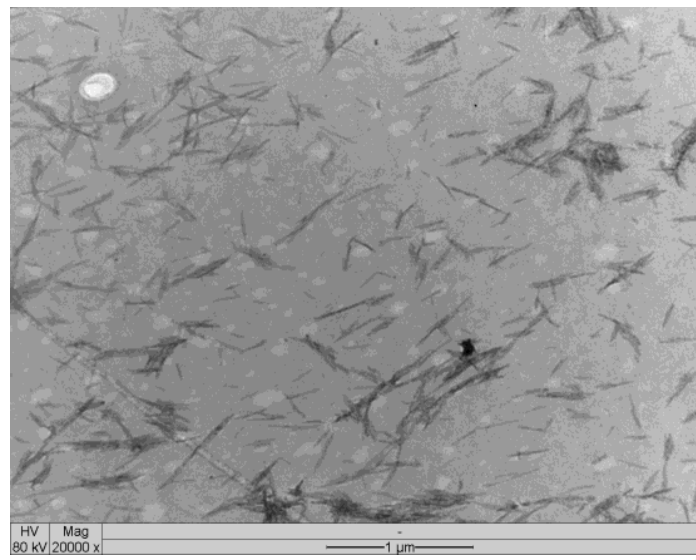

Figura 1 - Micrografia obtida por MET de nanocristais de algodão.

Pode-se observar que, pelo método utilizando as imagens da microscopia de transmissão, o valor médio para o tamanho dos nanocristais é em torno de $200 \mathrm{~nm}$. De acordo com as imagens, podem ser observados nanocristais de forma individualizada. Os nanocristais se apresentaram com aspecto morfológico semelhantes aos nanocristais encontrados na literatura, ou seja, em forma de agulhas com elevada relação comprimento largura como observado nos trabalhos de Rosa et al. (2010), Teixeira et al .(2011), Nascimento et al. (2010), entre outros.

\subsection{Isotermas de adsorção}

As isotermas de adsorção de cálcio em amostras de polpa celulósica são apresentadas nas Figuras 2 e 3.

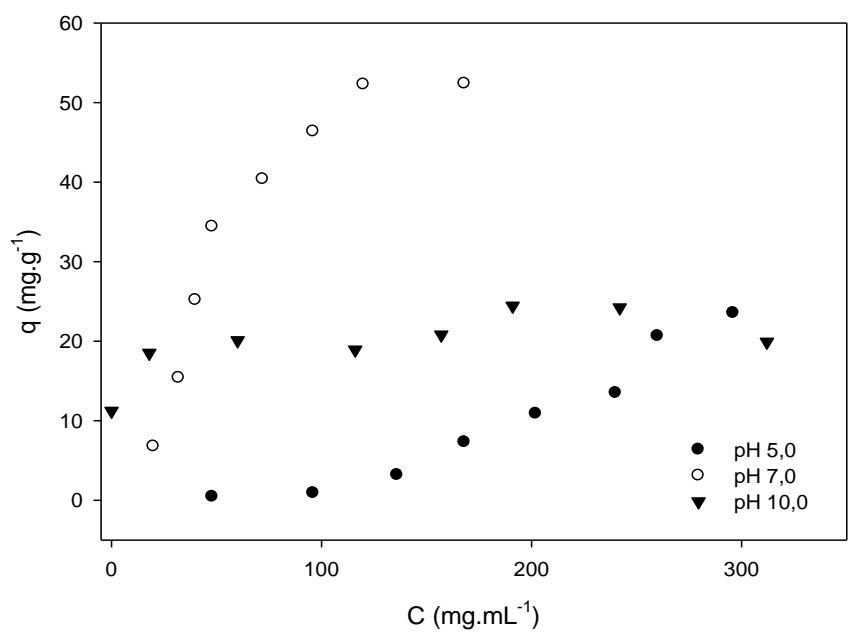

Figura 2 - Isotermas de adsorção de cálcio em polpa Kraft branqueada pura.

Os dados de equilíbrio não foram bem ajustados às equações de Langmuir e Freundlich, que se destacam como os modelos mais utilizados para interpretar ou predizer isotermas de adsorção (Crispim, 2009). 


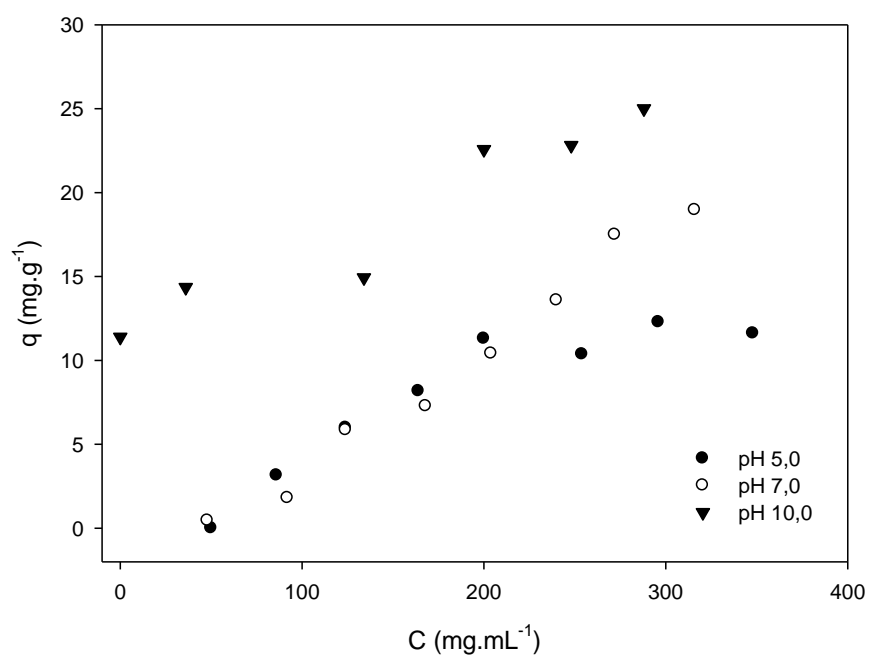

Figura 3 - Isotermas de adsorção de cálcio em polpa Kraft branqueada adicionada de CNC.

Assim, a maior concentração de cálcio utilizada nas isotermas (400 mg.mL ${ }^{-1}$ ) foi escolhida para realização da análise de absorção atômica. Os resultados obtidos para adsorção de cálcio em polpa Kraft adicionada de CNC são apresentados na Tabela 1.

Tabela 1 - Dados de adsorção de cálcio em polpa Kraft branqueada adicionada de CNC

\begin{tabular}{|c|c|c|c|c|}
\hline $\mathrm{pH}$ & $\mathrm{C}_{0}\left(\mathrm{mg} \cdot \mathrm{mL}^{-1}\right)$ & $\mathrm{C}\left(\mathrm{mg} \cdot \mathrm{mL}^{-1}\right)$ & $\mathrm{q}\left(\mathrm{mg}^{-} \mathrm{g}^{-1}\right)$ & $\%$ Extraída \\
\hline 5,0 & 400,00 & 254,56 & 165,27 & 36,36 \\
\hline 7,0 & 400,00 & 236,88 & 185,36 & 40,76 \\
\hline 10,0 & 400,00 & 209,36 & 216,63 & 47,66 \\
\hline
\end{tabular}

Foi possível verificar que a adsorção aumentou com o aumento do pH. A adsorção de cátions metálicos em soluções aquosas depende do $\mathrm{pH}$, pois o $\mathrm{pH}$ afeta o grau de ionização das espécies como as características da superfície do adsorvente, por causa da capacidade dos materiais modificados em adsorver prótons (Ayyappan et al., 2005). Em pH baixo, os cátions $\mathrm{H}^{+}$restringem a aproximação dos cátions metálicos, devido a repulsão causada pelas cargas equivalentes. Desse modo, com o aumento do $\mathrm{pH}$, os grupos funcionais passam ao estado ionizado com carga negativa, levando à atração dos cátions metálicos, e consequentemente a adsorção à superfície. "Karnitz Jr. (2007)" observou o mesmo comportamento estudando a adsorção de cálcio em bagaço de cana e obteve valor máximo de q de 52,3 mg.g ${ }^{-1}$.

\section{CONCLUSÃO}

A análise da isoterma de adsorção indicou que o sólido adsorvente estudado foi eficiente para adsorver íons cálcio, chegando a remover cerca de 47,66\% concentração inicial, na faixa de concentrações estudada. Assim, o CNC adicionado a polpa Kraft branqueada pode ser um método alternativo para substituir as resinas de troca iônica comerciais para remoção de íons cálcio de soluções aquosas. 


\section{REFERÊNCIAS}

AYYAPPAN, R. et al. Removal of $\mathrm{Pb}$ (II) from aqueous solution using carbon derived from agricultural wastes. Process biochemistry, 40,p. 1293-1299, 2005.

BAIRD, C. Química ambiental, 2ª Ed. Bookman, Porto Alegre, 2002.

BO ZHU; TONGXIANG FAN; DI ZHANG; Adsorption of copper ions from aqueous solution by citric acid modified soybean straw. Journal of Hazardous Materials, 153: 300, 2008.

BOEHM, P. H. Surfaces oxides on carbon and their analysis: a critical assessment. Carbon, 40: 145, 2002.

CHAKRAVARTY, S., PIMPLES, S., CHATURVEDI, H. T., SINGH, S., GUPTA, K. K. Removal of cooper from aqueous solution using newspaper pulp as an adsorbent. Journal of Hazardous Materials, 159: 396, 2008.

CHEREMISINOF, N.P. Handbook of water and wastewater treatment technologies. Butterworth Heinemann. Woburn, 2002.

CRISPIM, S. C. L. Remoção de cálcio em soluções aquosas por meio de carvões ativados submetidos a tratamentos superficiais. Tese de Doutorado. Universidade Federal da Paraíba. 2009.

DE MELO, J. C. P. Dissertação de Mestrado: Síntese e caracterização de derivados de celulose modificada com anidridos orgânicos - adsorção e termodinâmica de interação com cátions metálicos. Universidade Estadual de Campinas, Instituto de Química, Campinas - SP, fevereiro 2007.

DONG H., STRAWHECKERA K. E., SNYDERA J. F.. Cellulose nanocrystals as a reinforcing material for electrospun poly(methyl methacrylate) fibers: formation, properties and nanomechanical characterization. Carbohydrate Polymers, 87(4), 2488$2495,2012$.

KADIRVELU, K.; THAMARAISELVI, K.; NAMASIVAYAM, C. Removal of metals from industrial wastewaters by adsorption onto activates carbon prepared from an agricultural solid waste, Bioresource Technology, 76: 63, 2001.

KARNITZ Jr., O. Modificação química do bagaço de cana e celulose usando anidro do EDTA. Uso destes materiais na adsorção de metais pesados em solução aquosa. Minas Gerais, Programa de pós-graduação em recursos hídricos. Universidade Federal de Ouro Preto, 2007, Dissertação de Mestrado.

KOBYA, M.; DEMIRBAS, E.; SENTURK, E.; INCE, M. Adsorption oh heavy metal ions from aqueous solutions by activated carbon prepared from apricot stone. Bioresourece Tecnology, 96: 1518, 2005. 
MANAHAN, S.E. Fundamentals of environmental chemistry, $2^{\text {a }}$ Ed. CRC Press LLC. Boca Raton, 2001.

MEENA, A. K.; MISHRA, G.K.; RAÍ, P. K.; RAJAGOPAL, C.; NAGAR, P. N. Removal of heavy metal ions from aqueous solutions using carbon aerogel as an adsorbent. $J$. of Hazardous Materials, 122: 161, 2005.

MENDHAM, J.; DENNEY, R.C.; BARNES, J.D.; THOMAS, M.J.K. VOGEL. Análise Química Quantitativa. 6. ed. Rio de. Janeiro: LTC, 2002.

MOREIRA, C.S. Adsorção competitiva de cádmio, cobre, níquel e zinco em solos. Piracicaba, 2004. Dissertação (Mestrado) - Escola superior de agricultura. Universidade de São Paulo.

NASCIMENTO, D.M. Thermal and structural characteristics of waste derived biomass for potential.

NUNES, J.A. Tratamento físico-químico de águas residuárias industriais. $4^{\mathrm{a}}$ Ed. Editora J. Andrade. Aracaju, 2004.

ORLANDO, U. S.; BAES, A. U.; NISHIJIMA, W.; OKADA, M. Preparation of chelating agents from sugarcane bagasse by microwave radiation as an alternative ecologically benign procedure. Green Chemistry, v 4, P. 555-557,2002.

ROSA, M. F. Cellulose nanowhiskers from coconut husk fibers: Effect of preparation conditions on their thermal and morphological behavior. Carbohydrate Polymers, vol 81, p. 83-92,2010.

SONESSO, M. F. C. Obtenção e caracterização de nanocristais de celulose a partir de algodão cru e polpa kraft. Dissertação de mestrado. Universidade Federal de Santa Catarina, Florianópolis, SC, 2011.

SPAGNOL, C.,RODRIGUES, F.H.A.,NETO, A.G.V.C., PEREIRA, A.G.B., FAJARD A.R, RADOVANOVIC, E., RUBIRA, A.F., MUNIZ, E.C., Nanocomposites based on poly(acrylamide-co-acrylate) and cellulose nanowhiskers, European Polymer Journal, 2012, 48: p. 454-463.

SPINELLI, V. A.; LARANJEIRA, M. C. M.; FÁVERE, V. T.; KIMURA, I. Y. Cinética e equilíbrio de adsorção dos oxiânios Cr (VI), Mo (VI) e Se (VI) pelo sal de amônio quaternário de quitosana. Polímeros: Ciência e Tecnologia , 15: 218, 2005.

TEIXEIRA, E.M., et. al. Sugarcane Bagasse Whiskers: Extractions and Characterization. Industrial Crops and Products, vol 33, p.63-66, 2011.

WHO. Guidelines for Drinking-water Quality. Volume 1, $3^{\text {a }}$ Ed. WHO library, Geneva, 2004.

ZHOU C, YUE Y, ZHANG Q. Application of rod-shaped cellulose nanocrystals in polyacrylamide hydrogels. J Colloid Interface Sci, 2011;353:116-23. 